\title{
VADIOS E BARÕES NO OCASO DO IMPERRIO: O DEBATE SOBRE A REPRESSÃO DA OCIOSIDADE NA CÂMARA DOS DEPUTADOS EM 1888
}

\author{
Sidney Chalhoub
}

\section{INTRODUÇÃO}

A transição do trabalho escravo para o trabalho livre no Brasil do século XIX colocou as classes dominantes da época diante da necessidade premente de realizar reajustes no seu universo mental, de adequar a sua visão de mundo às transformações sócio-econômicas que estavam em andamento. No mundo de outrora, ordenado pela presença do escravo, a questão do trabalho era escassamente problematizada na esfera das mentalidades: o trabalhador escravo era propriedade do senhor e, sendo assim, o mundo do trabalho estava obviamente circunscrito à esfera mais ampla do mundo da ordem, que consagrava o princípio da propriedade. 1

O mundo do trabalho, no entanto, passou a virar um problema, a partir de meados do século XIX, quando a abolição do tráfico negreiro obrigou os barões do império a pensar o fim da propriedade escrava. Ao longo de toda a segunda metade do século, o escravo foi impondo seus atributos de homem, negando sua coisificação e, assim, provocando a necessidade das classes dominantes de pensar em um novo modo de inseri-lo na sociedade, agora como trabalhador livre. O Ministro da Justiça, em 1888, Ferreira Vianna, reconstitui, de forma um tanto patética, o processo que culminou na lei de 13 de maio:

"Já dizia Cícero que a escravidão não se podia manter, quando o senhor não dispunha do escravo como do seu boi, do seu arado, do seu carro. Era preciso que dele pudesse usar e abusar.

Desde que o escravo adquiria um direito, o senhor perdia na autoridade, e a escravidão estava ameaçada de extinção. 
V. Ex. conhece a história desta instituição, se tal nome merece o fato da escravidão. Desde - começo, não se reconheceu no escravo uma besta, mas um homem; tinha direitos, que impunham ao senhor deveres.

Esses direitos cresceram, alargaram-se, foram mais e mais atendidos pelo legislador, mandados respeitar.

Um dia, o instrumento, o boi, o arado, pelo sopro do legislador, levantou-se; tomou as formas do homem; pôs-se em pé, e disse ao poder público, armado desde a cabeça aos pés: - Eu sou livre; fostes vós que reconhecestes o meu direito; eu sou livre; não me rendo, prefiro a morte!" (Sensação) (vol. 3, p. 240)2

O processo de transição do trabalho escravo para o trabalho livre deixou os barōes do império diante de um problema bastante real: era necessário garantir que 0 liberto se tornasse um trabalhador. Por um lado, este problema tinha seu aspecto prático, que se traduzia na tentativa de propor medidas que obrigassem o indivíduo ao trabalho. Por outro lado, era preciso também um esforço de revisão de conceitos, de construção de valores que iriam constituir uma nova ética do trabalho. Em outras palavras, o trabalho precisava se despir de seu caráter aviltante e degradador característicos de uma sociedade escravista, assumindo uma roupagem nova que the desse um valor positivo, tornando-se assim o elemento fundamental para a implantação de uma ordem burguesa no Brasil.

Em seu sentido mais geral, este pequeno ensaio pretende abordar alguns aspectos das transformações no universo mental das classes dominantes enquanto contra-partida à transição do trabalho escravo para o trabalho livre, a partir de um estudo de caso - o debate sobre a repressão da ociosidade na Câmara dos Deputados em 1888. São dois os nossos objetivos principais: primeiro, acompanhar o esforço de elaboração, de construção de uma nova ética do trabalho; segundo, tentar desvendar como determinada visão do mundo do trabalho - e, por oposição, do mundo da ociosidade e do crime - se enquadra dentro do objetivo mais amplo das classes dominantes de preservar sua posição na estrutura social, ou seja, seu objetivo de manter a sociedade essencialmente tal como é. 
1 - Repercussões do 13 de maio: o fantasma da desordem.

O projeto de repressão à ociosidade de 1888 - elaborado pelo então Ministro da Justiça, Ferreira Vianna - começou a ser apreciado na Câmara dos Deputados em julho e sua discussão foi bastante marcada pelos ânimos ainda exaltados pelas repercussões da lei de 13 de maio. A utilidade do projeto foi votada quase que unanimemente pela Câmara, sendo que muitos deputados o viam como "de salvação pública para o Império do Brasil", exatamente porque tinha como objeto principal a "população nacional", ou seja, o liberto.

Havia um claro consenso entre os deputados de que a abolição trazia consigo a ameaça da desordem. Na mesma época em que o projeto sobre a ociosidade tramitavam na Câmara, um grupo de deputados, liderado por Lacerda Werneck e se identificando claramente com os interesses das "classes dos lavradores", dirige uma interpelação ao Ministro da Justiça, que visava exigir medidas do governo para garantir a defesa da propriedade e da segurança individual dos cidadãos, já que estas, de acordo com os interpelantes, estavam seriamente ameaçadas pelas ordas de libertos que supostamente vagavam pelas estradas a furtar e rapinar (sessão de 20 de julho, vol. 3, pp. 229-241).

Dramatizando ao máximo a situação, os deputados falam da solidão e do deserto a que ficaram reduzidas as fazendas de Vassouras, onde as "pacíficas e laboriosas populações locais" - isto é, os proprietários e suas familias - eram agora obrigadas a trabalhar dia e noite para "salvarem alguns caroços de feijão" que garantissem sua alimentação. Mais do que isto, a lei de 13 de maio era percebida como uma ameaça à ordem, porque nivelava todas as classes de um dia para o outro, provocando uma deslocação de profissões e de hábitos de conseqüências imprevisiveis. Para concluir, os interpelantes citavam diversos casos de crimes que teriam sido cometidos por libertos nos dias anteriores, provando assim o caos social que reinava especialmente nas províncias do Rio de Janeiro e de Minas Gerais. Como paliativo imediato para o problema, sugeria-se que os libertos fossem recrutados em massa para o exército.

Em sua resposta, Ferreira Vianna mostra claramente os exageros das afirmações dos interpelantes, e diz que uma das respostas do governo aos temores gerais de comprometimento da ordem é o projeto de repressão à ociosidade que estava em 
discussão na Câmara. O problema, portanto, é de ênfase e de decidir que medidas práticas tomar, contudo, havia, sem dúvida, o consenso de que a ordem estava ameaçada. Um dos pontos principais de toda esta discussão, por ocasião da interpelação, assim como do projeto sobre a ociosidade propriamente, é o consenso que se estabelece quanto ao suposto caráter do liberto. Em primeiro lugar, os libertos em geral eram pensados como individuos que estavam despreparados para a vida em sociedade. A escravidão não havia dado a estes homens nenhuma noção de justiça, de respeito à propriedade, de liberdade. A liberdade do cativeiro não significara para o liberto a responsabilidade pelos seus atos, e sim a possibilidade de se tornar ocioso, furtar, roubar, etc. Os libertos traziam em si os vícios de seu estado anterior, não tinham a ambição de fazer o bem e de obter um trabalho honesto, e não eram "civilizados" o suficiente para se tornarem cidadãos plenos em poucos meses. Era necessário, portanto, evitar que os libertos comprometessem a ordem, e para isto havia de se reprimir os seus vícios. Estes vicios seriam vencidos através da educação, e educar libertos significava criar o hábito do trabalho através da repressão, da obrigatoriedade. Este era exatamente o objetivo do projeto de Ferreira Vianna, como bem resume o deputado Mac-Dowell:

"Votei pela utilidade do projeto, convencido, como todos estamos, de que, hoje, mais do que nunca, é preciso reprimir a vadiação, a mendicidade desnecessária, etc... Há o dever imperioso por parte do Estado de reprimir e opor um dique a todos os vícios que o liberto trouxe de seu antigo estado, e que não podia o efeito miraculoso de uma lei fazer desaparecer, porque a lei não pode de um momento para outro transformar o que está na natureza.

... a lei produzirá os desejados efeitos compelindo-se a população ociosa ao trabalho honesto, minorando-se o efeito desastroso que fatalmente se prevê como conseqüência da libertação de uma massa enorme de escravos, atirada no meio da sociedade civilizada, escravos sem estímulo para o bem, sem educação, sem os sentimentos nobres que só pode adquirir uma população livre e finalmente será regulada a educação dos menores, que se tornarão instrumentos do trabalho inteligente, cidadãos 
morigerados, .... servindo de exemplo e edificação aos outros da mesma classe social." (vol. 7, pp. 259-260)

2 - A construção do consenso: em busca de uma nova ética do trabalho.

\section{1 - O mundo do trabalho.}

Em síntese, o que vimos até agora mostra que o problema real, para os parlamentares do imperador, era transformar o liberto em trabalhador. Tomava-se como ponto de partida o suposto de que todos os libertos eram ociosos, o que visava garantir, de início, o direito da "sociedade civilizada" em emendá-los. Mas a transformação do liberto em trabalhador não podia se dar apenas através da repressão, da violência explicita. Afinal, não se desejava um retorno a alguma forma disfarçada da hedionda instituição da escravidão. Que fazer, então? Bem, era necessário educar os libertos. Educar significa incutir no individuo "essas grandes qualidades que tornam um cidadão útil e o fazem compreender os seus deveres e os seus direitos". (vol. 6, p. 152). Ora, que grandes qualidades são estas que fazem de um indivíduo um cidadão "útil", "de caráter"? O amor e o respeito religioso à propriedade são, sem dúvida, qualidades fundamentais do bom cidadão. Mas este não é o ponto essencial a enfatizar neste contexto. Estamos pensando nos libertos, e não convém alimentar nestes indivíduos o sonho de se tornarem proprietários. Nada disso! Seria perigoso; seria jogar os pobres contra os ricos, uma crueldade! Para o liberto, tornar-se bom cidadão significa amar o trabalho em si, independentemente das vantagens materiais que possam dai advir. Educar o liberto significa transmitir-lhe a noção de que o trabalho é o valor supremo da vida em sociedade; o trabalho é o elemento característico da vida "civilizada". Mas como pensar no trabalho como algo positivo, nobilitador, em uma sociedade que foi escravista durante mais de três séculos? Como "convencer" o liberto a ser trabalhador, logo ele, recém advindo da escravidão? Mais do que isto, como justificar as nossas próprias medidas repressivas visando garantir a organização do trabalho? Afinal, as lavouras precisam de braços...

Os debates sobre o projeto de repressão à ociosidade mostram claramente a tentativa dos parlamentares de precisar o conceito de trabalho e seu significado no mundo em que viviam. Procurava-se uma justificativa ideológica para o trabalho, isto é, razões que pudessem justificar a sua obrigatoriedade 
para as classes menos favorecidas da estrutura social. A construção do conceito de trabalho passa por diversas etapas. A noção primeira e fundamental é a de que o trabalho é o elemento ordenador da sociedade, a sua "lei suprema" (vol. 3, p. 73). O cidadão recebe tudo da sociedade, pois esta lhe garante a segurança, os direitos individuais, a liberdade, a honra, etc. $O$ cidadão, portanto, está permanentemente endividado com a sociedade e deve retribuir o que dela recebe com o seu trabalho. Um discurso do deputado liberal Rodrigues Peixoto ilustra bem o consenso neste ponto:

Em todos os tempos, o trabalho foi considerado o primeiro elemento de uma sociedade bem organizada. Cada membro da comunidade deve a esta uma parte do seu tempo e do seu esforço no interesse geral, cuja inobservância apresenta gravidade, o que autoriza de certo modo a intervenção do Estado.

... é preciso que tenham todos uma ocupação, porque V. Ex. sabe que, desde que o indivíduo respira, como que contrai uma divida com a sociedade, a qual só pagará com o trabalho. (vol. 6, pp. 150 e 153)

Outro ponto fundamental é a relação que se estabelece entre trabalho e moralidade: quanto mais dedicação e abnegação o indivíduo tiver em seu trabalho, maiores serão os seus atributos morais. Uma das justificativas ideológicas fundamentais para o projeto era a intenção de moralizar o indivíduo pelo trabalho. Era preciso incutir nos cidadãos o hábito do trabalho, pois esta era a única forma de regenerar a sociedade, protegendo-a dos efeitos nocivos trazidos por centenas de milhares de libertos - individuos sem nenhum senso de moralidade. Dentro deste espírito, o projeto prevê que os ociosos serão conduzidos a colônias de trabalho, com preferência para atividades agrícolas, onde serão internados com o objetivo de adquirir o hábito do trabalho. Esta retórica moralista mal acoberta o objetivo dos legisladores: a pena para o ocioso devia ser bastante longa (de 1 a 3 anos para o reincidente), pois o que se desejava não era a punição pura e simples do indivíduo, mas sim sua reforma moral - e este objetivo não podia ser alcançado a curto prazo. A severidade das penas, portanto, se explica pelo seu caráter educativo, de regeneração moral do condenado, como expressa o relator da comissão parlamentar encarregada de dar um parecer inicial sobre o projeto: 
Desde que o objetivo é a correção moral, evidentemente eram insuficientes, para se alcançar esse objetivo, as disposições penais do nosso Código Criminal, que estabelecem a prisão de 9 a 24 dias; era necessário corrigir um ato inverterado, por conseguinte, fazê-lo substituir por outro, regenerando, fazendo adquirir o amor ao trabalho, pela prática do trabalho. Ora, um hábito desses não se adquire em pouco tempo...

O projeto previa ainda que uma parte do dinheiro obtido através do trabalho dos condenados, nos estabelecimentos correcionais, seria depositado em um fundo, e cada condenado receberia um certo pecúlio por ocasião de sua saida da prisão. O objetivo aqui era também educacional, pois visava formar no indivíduo a ambição de possuir alguma coisa através de uma atividade honrada. Toma-se o cuidado de não dar a este "possuir" a conotação de esperança de adquirir propriedade o que se pensa aqui é em incutir no indivíduo o hábito de ser econômico e de viver mais confortavelmente, pois estes hábitos o estimulariam para o trabalho. (vol. 6, p. 152).

De qualquer forma, o respeito religioso à propriedade é consagrado no projeto no item das circunstâncias agravantes na prática da vadiagem: um dos agravantes da pena era quando o indivíduo possuidor de certa fortuna acaba por esbanjá-la, ficando na miséria e sem condições de sustentar a família. $O$ debate deste item mostra o paradoxismo a que pode chegar este respeito devido à propriedade como, por exemplo, quando um dos deputados não concorda que um indivíduo que esbanja sua fortuna tenha sua pena agravada, já que o que tal individuo precisaria era de um tratamento médico, pois só poderia estar louco! Diz o deputado:

Ora, S. Ex. sabe que quase sempre a prodigalidade é inerente a uma enfermidade, porque ninguém, na integridade das suas faculdades, porá fora aquilo que possui.

Sabe ainda S. Ex. que todos nós temos amor aos nossos bens, ao fruto do nosso trabalho ou ao que de outrem herdemos. Por conseqüência, um indivíduo que esbanja aquilo que possue, que perde 0 amor a propriedade, não é simplesmente um viúvo: é principalmente 
um enfermo e a circunstância do esbanjamento não deve ser para ele um agravante." (vol. 6, p. 156)

Resta abordar ainda como estes parlamentares percebiam a relação patrão-empregado neste mundo do trabalho em processo de construção ideológica. O paternalismo é o elemento fundamental neste contexto: a autoridade do patrão é enfatizada e considerada essencial para que o trabalhador se veja obrigado a desempenhar suas tarefas com a eficiência exigida, mas os possiveis excessos na autoridade patronal são dissimulados sob a forma da proteção, da orientação que o bom patrão devia a seus trabalhadores passivos e abnegados. Diz o deputado Rodrigues Peixoto:

O patrão, depois de celebrado o contrato, se constitui uma espécie de juiz doméstico e tem ação incontestável sobre o trabalhador, para guiá-lo e aconselhá-lo. Se alguma vez esse indivíduo sai das órbitas legais e pratica alguma falta ou delito ligeiro, que não precisa ser punido pela lei, o próprio patrão, em virtude do regulamento que ali existe, e que estabelece direitos e deveres entre locatário e locador, lhe inflige castigos moderados, como aqueles que infligem os pais aos filhos. (vol. 6, p. 151)

\section{2 - O mundo da ociosidade e do crime.}

O conceito de vadiagem se constrói nas mentes dos nossos barões basicamente a partir de um simples processo de inversão: todos os predicados associados ao mundo do trabalho são negados quando o objeto de reflexão é a vadiagem. Assim, enquanto o trabalho é a lei suprema da sociedade, a ociosidade é uma ameaça constante à ordem. O ocioso é aquele indivíduo que, negando-se a pagar sua dívida para com a comunidade através do trabalho honesto, coloca-se à margem da sociedade e nada produz para promover o bem comum.

Há, portanto, uma incompatibilidade irredutivel entre manutenção da ordem e ociosidade. Mas era essencial para os nossos deputados uma melhor compreensão das causas da ociosidade do trabalhador brasileiro. É notório o fato de que o nacional não é amigo do trabalho; vejam só, por exemplo, o caipira paulista, "um verdadeiro parasita, que consome apenas e nada produz." (vol. 6, p. 227). Como explicar esta anomalia? 
Um dos deputados nos dá uma explicação didática, elaborando um conceito que ele chama de "lei da necessidade" (vol. 6, p. 152). Segundo ele, nos países europeus e asiáticos se acha realizada a teoria de Malthus e Ricardo, ou seja, há um excesso de população em relação à capacidade de produzir viveres. A vida é bastante dura para estas populações, que se sentem então estimuladas para o trabalho pela própria necessidade de lutar pela sobrevivência. No Brasil, ao contrário, o individuo encontra muitas facilidades para subsistir, pois 0 nosso solo é rico, o nosso clima ameno, e a abundância se nota por toda parte. Sendo assim, a nossa população não precisa ter hábitos ativos de trabalho, pois tem facilidade em obter a carne, o peixe, o fruto, e, além disso, a amenidade do clima permite ao brasileiro passar perfeitamente ao relento, sem cobrir o corpo com vestes pesadas e caras. Em nosso país, portanto, é preciso obrigar o individuo ao trabalho, pois a tentação da ociosidade é irresistivel.

Mas a ociosidade deve ser combatida não só porque negando-se ao trabalho o indivíduo deixa de pagar sua divida para com a sociedade, mas também porque o ocioso é um pervertido, um viciado que representa uma ameaça à moral e aos bons costumes. Um indivíduo ocioso é um indivíduo sem educação moral, pois não tem noção de responsabilidade, não tem interesse em produzir o bem comum e nem possui respeito pela propriedade. Sendo assim, a ociosidade é um estado de depravação de costumes que acaba levando o indivíduo a cometer verdadeiros crimes contra a propriedade e a segurança individual. Em outras palavras, a vadiagem é um ato preparatório do crime, daí a necessidade de sua repressão. Assim se expressa a comissão parlamentar que estudou o projeto:

"O projeto... revela a intenção de orientar espíritos transviados, corrigir disposições viciosas, antes que punir criminosos.

Se o legislador tem o imprescindivel dever de consagrar no direito positivo prescrições tendentes à repressão dos crimes que atentam à ordem social, não the é lícito desconhecer que esses atos derivam-se, o mais das vezes, do relaxamento ou da depravação dos costumes, tendo geralmente como causa geradora a ociosidade." (vol. 6, p. 68).

Outro fato interessante é a relação estabelecida entre ociosidade e pobreza. $O$ código criminal vigente na época e o 
próprio projeto em discussão reconheciam que eram duas as condições elementares para que ficasse caracterizado o delito da vadiagem: o hábito e a indigência, especialmente a última. Se um indivíduo é ocioso, mas tem meios de garantir sua sobrevivência, ele não é obviamente perigoso à ordem social. Só a união da vadiagem com a indigência afeta o senso moral, deturpando o homem e engendrando o crime. Fica claro, portanto, que existe uma má ociosidade e uma boa ociosidade. A má ociosidade é aquela caracteristica das classes pobres, e deve ser prontamente reprimida. A boa ociosidade é atributo dos barões.

Os homens do imperador reconhecem abertamente, portanto, que se deseja reprimir os miseráveis. Passam a utilizar, então, o conceito de "classes perigosas", avidamente aprendido nos compêndios europeus da época. Segundo Alberto Passos Guimarães, o termo "classes perigosas" apareceu originalmente na Inglaterra e se refere às pessoas que já houvessem passado pela prisão ou as que, mesmo ainda não tendo sido presas, haviam optado por obter o seu sustento e o de sua familia através da prática de furtos e não do trabalho. Esta utilização do termo, por conseguinte, é bastante restrita, referindo-se apenas aos indivíduos que já haviam abertamente escolhido uma estratégia de sobrevivência que os colocava à margem da lei. Os nossos deputados, contudo, citam principalmente autores franceses e alargam consideravelmente as proporções do termo. Os legisladores brasileiros utilizam o termo "classes perigosas" como sinônimo de "classes pobres", e isto significa dizer que o fato de ser pobre torna o indivíduo automaticamente perigoso à sociedade. Os pobres apresentam maior tendência à ociosidade, são cheios de vícios, menos moralizados e podem facilmente "rolar até o abismo do crime". Diz um dos deputados:

"As classes pobres e viciosas... sempre foram e hão de ser sempre a mais abundante causa de todas as sortes de malfeitores: são elas que se designam mais propriamente sob o título de - classes perigosas -; pois quando mesmo o vício não é acompanhado pelo crime, só o fato de aliar-se à pobreza no mesmo indivíduo constitui um justo motivo de terror para a sociedade. $\mathrm{O}$ perigo social cresce e torna-se de mais a mais ameaçador, à medida que o pobre deteriora a sua condição pelo vício e, o que é pior, pela ociosidade." (vol. 3, p. 73). 
3.3 - Os pontos de divergência.

Até agora temos nos preocupado apenas em reconstruir os pontos de consenso elaborados pelos deputados durante o debate sobre o projeto de repressão à ociosidade em 1888. É lícito perguntar agora em que pontos havia divergência entre os deputados, pois, afinal, não se gastariam vários meses a discutir um projeto de lei sobre o qual quase todos concordavam.

De um lado, a demora das discussões se explica pelo próprio esforço de construção de uma nova ética do trabalho em uma conjuntura de transição da escravidão para o trabalho livre que era percebida por todos como crítica. No entanto, o consenso sobre conceitos como trabalho, ociosidade, crime, classes perigosas, etc. se estabelece com relativa rapidez, assim como facilmente se concorda com a idéia de que algo deve ser feito para garantir a organização do trabalho. Por outro lado, muitas sessões legislativas são gastas em discussões de pormenores ou de questões práticas ligadas à aplicação do projeto, como a duração exata da pena em cada caso, qual a palavra mais precisa neste ou naquele contexto, como deveriam ser os estabelecimentos correcionais que seriam construídos especialmente para os ociosos, o custo exato da aplicação do projeto, etc. Em suma, as divergências se localizavam quando da tentativa de tirar medidas práticas para tornar viável a realização do projeto.

Apenas um deputado do partido liberal, Aristides Spinola, discursou longamente na Câmara com o intuito de fazer uma crítica virulenta do projeto e justificar seu voto contrário ao mesmo. Este deputado revive a velha retórica político-partidária de todo o império, e seu discurso se constrói na oposição entre centralização e poder local. Para Spinola, o projeto alargava demasiadamente as atribuições do Estado, ferindo assim a autonomia local e tornando-se completamente inexequível. De qualquer forma, este deputado está longe de discordar dos pontos fundamentais de consenso, admitindo claramente a ociosidade como um mal que deve ser combatido com medidas visando a organização do trabalho. Sua discordância se dá quanto à melhor estratégia política para obter esta organização do trabalho: para ele todas as iniciativas de repressão à vadiagem deviam ser tomadas pelas municipalidades e pelas províncias, e não pelo poder central. Assim ele resume a sua oposição ao projeto: 
"Em suma, senhores, voto contra o projeto porque vejo nele a ação enervadora e prejudicial do Estado, invadindo domínios, que the devem ser vedados; porque contém em seu bojo males que cumpre evitar; porque não traz remédios aos males que pretende curar; porque nada adianta para a organização do trabalho; porque é dispendioso, vexatório, iniquo e ineficaz." (vol. 6, p. 444).

Não se pode sequer concluir, contudo, que a política partidária sempre informava as posições dos deputados nas discussões quanto a aspectos práticos ou de estratégia política do projeto. As críticas ao projeto estavam muito mais determinadas pela conjuntura política do momento do que propriamente pelos velhos partidos do império: por exemplo, um grupo de deputados conservadores, identificados com os interesses da lavoura, aproveita a ocasião da discussão do projeto para criticar abertamente o gabinete conservador que havia cometido o sacrilégio de abolir a escravidão.

Em resumo, o espírito de todo este debate sobre a repressão da ociosidade é perfeitamente exprimido nas palavras seguintes do deputado Paes Leme:

“. . não terei dúvida em louvar atos e decisões como as de que se trata neste projeto, porque o meu mais ardente desejo é que o meu país caminhe, e que estas questões partidárias fiquem de lado, e que nós imitemos, principalmente, os países novos que aproveitam bem o seu tempo." (vol. 6, p. 228)

3 - Ideologia e controle social: a inserção dos "pervertidos" no mundo dos "morigerados".

O universo ideológico das classes dominantes brasileiras, no ocaso do império, parece estar dividido em dois mundos que se definem por sua oposição um ao outro: de um lado, há o mundo do trabalho, de outro, há o mundo da ociosidade e do crime. No discurso dominante, o mundo da ociosidade e do crime está à margem da sociedade civil - isto é, trata-se de um mundo marginal, que é concebido como a imagem invertida do mundo virtuoso da moral, do trabalho e da ordem. Deste mundo às avessas - amoral, vadio e caótico - fazem parte centenas de milhares de libertos e ainda outros tantos brasi- 
leiros pobres. Mais do que isto, este mundo é uma aberração, devendo ser reprimido e controlado para que não comprometa a ordem.

Portanto, um discurso ideológico dualista e profundamente maniqueista - baseado na melhor tradição cristã ocidental de procurar distinguir sempre o bem do mal, o certo do errado, etc. - é a característica fundamental da visão de mundo das classes dominantes brasileiras na época estudada. Mas este discurso ideológico dualista tem sido muitas vezes encampado pela produção historiográfica, ganhando assim reputação segura de um retrato fiel da realidade que ele procura espelhar. Sendo assim, os cientistas sociais brasileiros vêm repetindo ao infinito que o negro brasileiro permaneceu em uma posição de subordinação social nos anos pós-abolição. ${ }^{3}$ Os negros e mulatos estavam despreparados para a vida em liberdade, pois não sabiam conviver com as responsabilidades inerentes à condição de trabalhadores livres. Este estado de anomia ou patologia social era resultado do efeito desagregador da escravidão, que havia destruído quase todo o vestígio da herança cultural negra. A escravidão havia ainda destituído os negros de toda a vida familiar e de todas as formas de cooperação e assistência mútua baseadas na família. Por todas estas circunstâncias, a população de cor teria ficado excluída das oportunidades econômicas e sociais ofereciaas pela ordem social competitiva emergente, mergulhando em um estado patológico que se caracterizava por uma estrutura familiar falida, vadiagem, alcoolismo, promiscuidade, alto índice de criminalidade e outros elementos considerados sintomas de desajuste. Apesar da atualização da terminologia, este tipo de discurso sobre o liberto difere muito escassamente daquele veiculado pelos barões imperiais.

A documentação analisada parece permitir, contudo, pelo menos a nível de hipótese, a leitura de uma outra forma de inserção do liberto - isto é, do ocioso e do criminoso em potencial - no mundo dos morigerados. A visão de mundo dos homens do imperador postula um paralelismo perfeito entre a hierarquização da estrutura social e as diversas partes constituintes do universo ideológico. No nível mais elevado da hierarquia social nós temos os proprietários - patrões - seguidos de forma um tanto distante pelos bons trabalhadores. Neste nivel reina a ordem por excelência, já que os indivíduos aí localizados são aqueles de mais alto grau de moralidade, pois amam o trabalho e sabem respeitar a propriedade. No nivel inferior nós temos o mundo dos ociosos. Neste mundo existe 
um certo grau de depravação moral e uma tendência à desordem, pois estes individuos não respeitam a lei suprema da sociedade - o trabalho. Finalmente, temos o mundo do crime, que é formado pelos indivíduos de maus instintos, miseráveis e infensos aos ditames da ordem. Assim, cria-se um sistema segundo o qual o individuo mais bem situado na hierarquia social é sempre mais dedicado ao trabalho, mais moral e ordeiro do que o indivíduo que o precede. Ao contrário, quanto maior a pobreza do indivíduo, maior sua repulsa ao trabalho e menor a sua moralidade e seu apego à ordem.

Em outras palavras, o sistema se caracteriza por uma linha contínua que une o mais moral ao menos moral no universo ideológico, e o mais rico ao mais pobre na estrutura social. Neste sentido, não há um dualismo, uma oposição entre dois mundos diferentes; isto é, não há um mundo do trabalho e outro da ociosidade e do crime - há, na verdade, apenas um mundo, coerente e integrado na sua dimensão ideológica. Não faz sentido, então, pensar o ocioso e o criminoso como indivíduos que vivem à margem do sistema, marginais em relação a um suposto mundo da ordem. Cabe pensar a ociosidade e o crime como elementos constituintes da ordem, e mesmo como elementos fundamentais para a reprodução de determinado tipo de sociedade. Há de se questionar a visão tradicionalmente veiculada pelas classes dominantes brasileiras - tanto no passado quanto no presente - de que a vadiagem e o crime - e abdico aqui de problematizar a definição destes termos, por questões de tempo e espaço - são contradições dentro do sistema, simples conseqüências indesejáveis de suas deficiências. Em suma, a hipótese que se quer lançar aqui é a de que a existência da ociosidade e do crime tem uma utilidade óbvia quando interpretada do ponto de vista da racionalidade do sistema: ela justifica os mecanismos de controle e sujeição dos grupos sociais mais pobres. 4 Mais do que isto, já que ideologicamente quase se equivalem os conceitos de pobreza, ociosidade e criminalidade - são todos atributos das chamadas "classes perigosas" - então a decantada "preguiça" do brasileiro e a "violência inata" das classes populares servem como poderosos antídotos contra qualquer tentativa de estabelecer uma política social mais justa e igualitária. 
Notas

1 Este trabalho tem seu ponto de partida nas discussões de sala de aula do curso intitulado "Partidos Políticos no Império", no mestrado da UFF. Em muitos de seus aspectos, portanto, sinto-me em débito com a professora Margarida de Souza Neves e com os meus colegas de turma.

2 Todas as citações são provenientes dos Anais da Câmara dos Deputados, são de 1888. Assim, para facilitar as inđicações das referências, limitei-me a mencionar o volume e a página da citação entre parêntesis ao longo do texto.

3 Ver, por exemplo, Fernandes, Florestan, A Integração do Negro na Sociedade de Classes, São Paulo, Dominus e Editora da USP, 1964.

4 Ver, por exemplo, Ramalho, José Ricardo, Mundo do Crime: a ordem pelo avesso, Rio de Janeiro, Graal, 1979.

Universidade Federal de Ouro Preto

Departamento de História

Mariana - Brasil 